\title{
La motivación de las tareas digitales mediante "pseudo-ApS" en Biología Celular del grado en Medicina
}

\author{
Teresa San-Miguel ${ }^{a}$, Javier Megíasa ${ }^{a}$, Eva Serna ${ }^{b}$, Silvia Calabuiga, José Manuel Morales a, Carmina \\ Montoliua y Daniel Monleón $^{\text {a. }}$ \\ aDepartamento de Patología, Facultad de Medicina y Odontología, Universitat de València (teconsan@uv.es). \\ bDepartamento de Fisiología, Facultad de Medicina y Odontología, Universitat de València.
}

\begin{abstract}
The tutored groups of the subject "Biology" in the lst course of the degree in Medicine (Universitat de València) are an amazing environment to carry out activities that combine conceptual training with transversal development of skills. For this purpose, during the academic year 19-20, we have implemented the linking of the UV institutional account with Microsoft 365, thanks to the existing agreement between both entities to facilitate the use of Information and Communication Technologies (ICTS) in the management of the time and the information exchange. The students are proposed to elaborate their own and original learning objects, in animation format, which will be used during the next two years by other students and, ultimately, by external associations, in a project that tries to combine Service-Learning with the use of ICT in a context in which students are responsible for their own learning and that of their peers.
\end{abstract}

Keywords: pseudo-ApS, TICs, Microsoft Teams.

\section{Resumen}

Los grupos tutorizados de la asignatura "Biología" de $1^{\circ}$ de Medicina (Universitat de València) son un entorno estupendo en el que desarrollar actividades que aúnen el carácter formativo conceptual con el desarrollo competencial transversal. Para ello, en el curso 19-20, hemos implementado la vinculación de la cuenta institucional UV con Microsoft 365, gracias al convenio existente entre ambas entidades, para facilitar la utilización de las Tecnologías de la Información y la Comunicación (TIC) en la gestión del tiempo y del intercambio de información. Se propone a los alumnos la elaboración de objetos de aprendizaje propios y originales, en formato animación, que serán utilizados durante los próximos dos años por otros estudiantes y en último término, por asociaciones externas, en un proyecto que trata de aunar el Aprendizaje-Servicio con la utilización de las TIC en un contexto en que el alumno se hace responsable de su aprendizaje y del de sus compañeros.

Palabras clave: pseudo-ApS, TIC, Microsoft Teams.

\section{Introducción}

De acuerdo a las descripciones de los grandes estudios globales, como Educase Learning Initiative (NMC Educase, 2020) algunas de las necesidades en competencias básicas de los estudiantes universitarios son las habilidades para el mundo real, la capacidad de colaboración y la fluidez en el ámbito digital. Esta fluidez, va más allá de entender simplemente cómo usar la tecnología, e implica integrarla de manera real y eficaz en su práctica diaria y en su formación. Ha sido una tendencia en los últimos tiempos, el utilizar 
nuevos recursos y objetos de aprendizaje (OA) para transmitir la información, usando los materiales multimedia como una herramienta francamente útil en la mejora de la percepción del alumno hacia su construcción del conocimiento (Marquès, 2000).

Está ampliamente aceptado que la motivación, entendida como el deseo del alumno por aprender, es un factor determinante en su rendimiento académico (Roncel-Vega, 2007). Motivación y actitud hacia el aprendizaje son incluso más decisivas que la inteligencia, ya que se puede ejercer influencia sobre ellas (Luján-García, 1999). Así, se ha postulado que las imágenes animadas y los entornos gráficos atractivos son un elemento motivador excelente, habiéndose demostrado que favorecen la retención de información por el espectador/alumno (Salinas, 1996). Por esta razón, proporcionar información como material multimedia para ayudar al alumnado a comprender y destacar los conceptos más importantes, a la par que se abordan contenidos conflictivos y se mejora la motivación, es un punto fuerte en el aprendizaje (Polanco, 2005).

Otro elemento con gran potencial motivador es la conciencia de "utilidad" en las tareas que se ejecutan. Cuando el o la estudiante percibe su trabajo como "útil", más allá de su propio aprendizaje conceptual, la actitud hacia dicho aprendizaje mejora. De esta manera surge el "Aprendizaje-Servicio" (ApS) como potente herramienta motivacional. La necesidad del desarrollo competencial con las actividades adyacentes a la lección magistral participativa, es fundamental, y es en ese contexto, donde surge la actividad "grupos tutorizados" como campo en el que implementar innovaciones que aúnen estas necesidades en pro de mejorar los aprendizajes de nuestros alumnos. Asociando la utilidad del entorno gráfico/animado, la necesidad de motivar a nuestras alumnas y alumnos y el abordaje del desarrollo de las competencias digitales, se diseña esta intervención educativa en los grupos tutorizados de primero de Biología, con una concepción de "pseudo-ApS": la actividad propuesta servirá al alumnado para desarrollar competencias y aprender contenidos pero además, servirá para futuros compañeros que continuarán el trabajo de los anteriores.

Aunque el uso de las TIC está muy extendido en el ámbito académico universitario, existen ciertas limitaciones derivadas de la utilización de recursos digitales gratuitos, y es que en muchos casos, los alumnos deben registrarse con datos personales o correos electrónicos proporcionados por Google y otros proveedores. Esto hace que la normativa legal aplicable sea siempre delicada y resulte complicado instaurar la utilización de estas aplicaciones de manera obligatoria, ya que no se puede obligar a nadie a crearse un usuario en ninguna empresa externa. En este proyecto, tratamos también de resolver dicha cuestión.

\section{Objetivos}

Esta acción pretende como objetivo 1: implementar el uso de TIC a las que tenemos acceso desde la cuenta institucional de la UV, tanto el profesorado como el alumnado, gracias al convenio establecido entre la UV y la empresa Microsoft y que hasta la fecha, ha sido infrautilizado. De esta manera podemos canalizar la utilización de las TIC a través del correo institucional que la UV genera a todos sus usuarios, lo que supondría una excelente forma de evitar dilemas y problemas de índole legal.

Los grupos tutorizados de $1^{\circ}$ de Medicina-Biología ejecutan un trabajo colaborativo que presentan a los profesores de la asignatura. La gestión de los grupos y del encaje del escaso tiempo disponible del alumnado para las reuniones es tediosa, de manera que, en ocasiones, la cita se produce o bien antes de que haya habido avance en el trabajo o cuando la acumulación de dudas ya es demasiado grande. Así, el objetivo 2 es optimizar la gestión del tiempo y de la información mediante las TIC. 
El desarrollo de acciones educativas diferentes a las que se vienen ejecutando en años anteriores, como "factor sopresa" suma su efecto positivo a los elementos ya mencionados para el objetivo fundamental de estas acciones, que es mejorar la motivación del alumnado hacia el aprendizaje de la Biología (objetivo 3).

La naturaleza del diseño de esta acción implica la creación de objetos de aprendizaje dinámicos, de cara a desarrollar la competencia digital así como la creatividad de los alumnos para su diseño (objetivo 4).

Por último, estos materiales generados, podrán ser utilizados por siguientes promociones para incidir positivamente en su aprendizaje, en un sistema que podemos clasificar como "pseudo-ApS" (objetivo 5).

\section{Desarrollo de la innovación}

El trabajo se estructura en 3 etapas a lo largo de diferentes cursos, de manera que el alumnado adquiera un conocimiento más profundo sobre el funcionamiento de un orgánulo o estructura subcelular, sobre lo que le ocurre a sus elementos integrales desde una perspectiva morfológica, y sobre el impacto de esa morfología en la función. El alumnado deberá ser capaz de sintetizarlo y transmitirlo en un OA dinámico, para facilitar la asimilación a sus compañeros de cursos posteriores. Así, el alumnado del siguiente curso debería crear una versión mejorada de cada OA, en el que se ilustre el funcionamiento del orgánulo cuando está alterado en una condición biopatológica, además de sus consecuencias a nivel celular y su impacto sobre un fenotipo completo. La tercera fase llevaría al alumnado hasta el contacto con las asociaciones de afectados de dicha patología. En colaboración con ellas, podrían, mediante la mejora de los OA generados, colaborar en la comprensión de estas patologías para los afectados y familiares, o favorecer la difusión y comprensión de dichas patologías en la población general. Así, el proyecto cumple con un servicio pedagógico desde un público reducido en el primer año, algo más amplio en el segundo y con un mayor impacto social en el tercero.

En primer lugar se crea el grupo de trabajo "BioAnimat I", al amparo del proyecto UV-SFPIE_PID19109, para mejorar el uso de las herramientas de colaboración, dentro de Microsoft Teams. Teams es un espacio de trabajo basado en chat, lo que, por definición, pretende mejorar la comunicación de los equipos de trabajo, facilitando la colaboración. Se dirige específicamente al grupo L8 de $1^{\circ}$ de Medicina formado por 34 alumnos.

A través de la opción "archivos", se comparte con el alumnado un documento resumen de instrucciones que se presenta en el aula, explicando paso a paso, en qué consiste la actividad, etapas y detalles para su elaboración.

El alumnado recibe una descripción de las actividades que se han hecho en años anteriores y las razones metodológicas para su diseño y a continuación, se explica la motivación del profesorado para implementar esta actividad como "pseudo-ApS" y las mejoras que podría suponer sobre las activades anteriores.

Se proponen 8 temas a repartir entre los alumnos, para generar 8 objetos de aprendizaje. El docente genera los grupos de trabajo, garantizando la participación de al menos un estudiante por grupo, con percepción de alta competencia digital. Se forman 6 grupos de 4 personas y 2 grupos de 5 personas. Se permite al alumnado elegir entre los temas propuestos. Se comparte un calendario de reuniones con cada grupo. Mediante la herramienta PLANNER se especifica el objetivo para cada fecha. Mediante PDF se comparte el horario completo, que irá adaptándose a las necesidades del alumnado. 
En la primera reunión se pide el contenido teórico detallado que se va a abordar en el OA a presentar, de cara a detectar posibles errores conceptuales. Hay que tener en cuenta que los temas se han seleccionado, teniendo en cuenta como elemento motivador, los cuadros clínicos y las respercusiones fenotípicas de las alteraciones en los orgánulos. Sin embargo, también se ha tenido en cuenta que fueran procesos que ofrecen una alta dificultad abstracta para su comprensión. Ahí radica la importancia de un buen detalle en los aspectos teóricos.

En la segunda reunión se pide el boceto en papel de la animación que presentarán. La finalidad es ayudar al alumnado a estructurar en imágenes los procesos, sin dejar etapas clave por ilustrar.

En la tercera reunión se pide el OA completo junto con el discurso que se pretende presentar. Así, la función de esta reunión es resolver dudas o detectar errores de cara a la exposición del proceso biológico que presentan.

Se da como optativa una $4^{\mathrm{a}}$ reunión, previa a la exposición de los trabajos para reforzar la seguridad del alumnado de cara a la exposición pública de la actividad.

La $5^{\text {a }}$ fecha se convoca en el aula de teoría. Se invita a los alumnos no implicados en esta actividad, de otro subgrupo de prácticas y a los docentes. La sesión consiste en la exposición por parte de cada grupo, del segmento de contenidos que se ha adjudicado, con el apoyo visual del OA que han generado.

\section{Resultados}

\subsection{La aceptación del trabajo es máxima.}

En comparación con la otra mitad de su grupo teórico, la aceptación es del 100\% de los miembros del grupo: teniendo opción de elegir el formato clásico de trabajo tutorizado, que es hacer una búsqueda bibliográfica sobre un orgánulo y una patología concreta asociada a su disfunción, y presentarla en formato póster delante de sus compañeros, el 100\% de los alumnos aceptan participar en esta innovación. El grupo diana se muestra entusiasmado con tener que manejar la bibliografía recomendada y profundizar en el contenido teórico abordado en clase. Manifiestan en las reuniones mantenidas, que encuentran muy práctico tener que preparar una explicación sintética y una animación digital, además de preparar una exposición oral en torno a la animación. Dada la diferencia de esfuerzo requirida entre ambos grupos, se ofrece la posibilidad de cambiar de opción al formato clásico tras la primera sesión. A pesar de requerir mayor esfuerzo, todos los alumnos a los que se ofreció la innovación, se acogieron a esta modalidad de trabajo tutorizado y ninguno cambió de opción a lo largo del proceso.

\subsection{La participación mediante Teams es media.}

La vinculación de la cuenta institucional a Microsoft 365 vía UV es opcional, puesto que, a pesar del fuerte esfuerzo institucional en facilitar a la comunidad universitaria el acceso a estas potentes herramientas de trabajo, no se obligó el uso de manera individual; se distribuyeron las instrucciones pero solo se exigió que al menos un miembro de cada equipo lo hiciera. Así, solo el $52.3 \%$ de las y los estudiantes vincularon su cuenta UV (19 de 34). Solo 10 de los 19 alumnos que vincularon su cuenta, participaron activamente en los chats. Esto representa una consecución del objetivo 1 media. Dada la posterior situación excepcional a causa de la pandemia de COVID-19, habría sido muy positivo para el alumnado haberse familiarizado con este entorno durante esta experiencia.

No obstante, para los usuarios, la interfaz Teams resulta cómoda y atractiva. Permite monitorizar la actividad de los alumnos dentro del grupo, facilita el incrustado de multitud de aplicaciones accesorias, 
hace que la comunicación sea fluída gracias a un chat persona-tutor y a un chat grupal y resulta muy visual el control de los plazos y las tareas (figura 1). Gracias al representante de cada grupo que utilizó los chats para la tutorización, se facilitó la comunicación profesorado-alumnado y se mejoró la gestión del tiempo en relación al objetivo 2 .

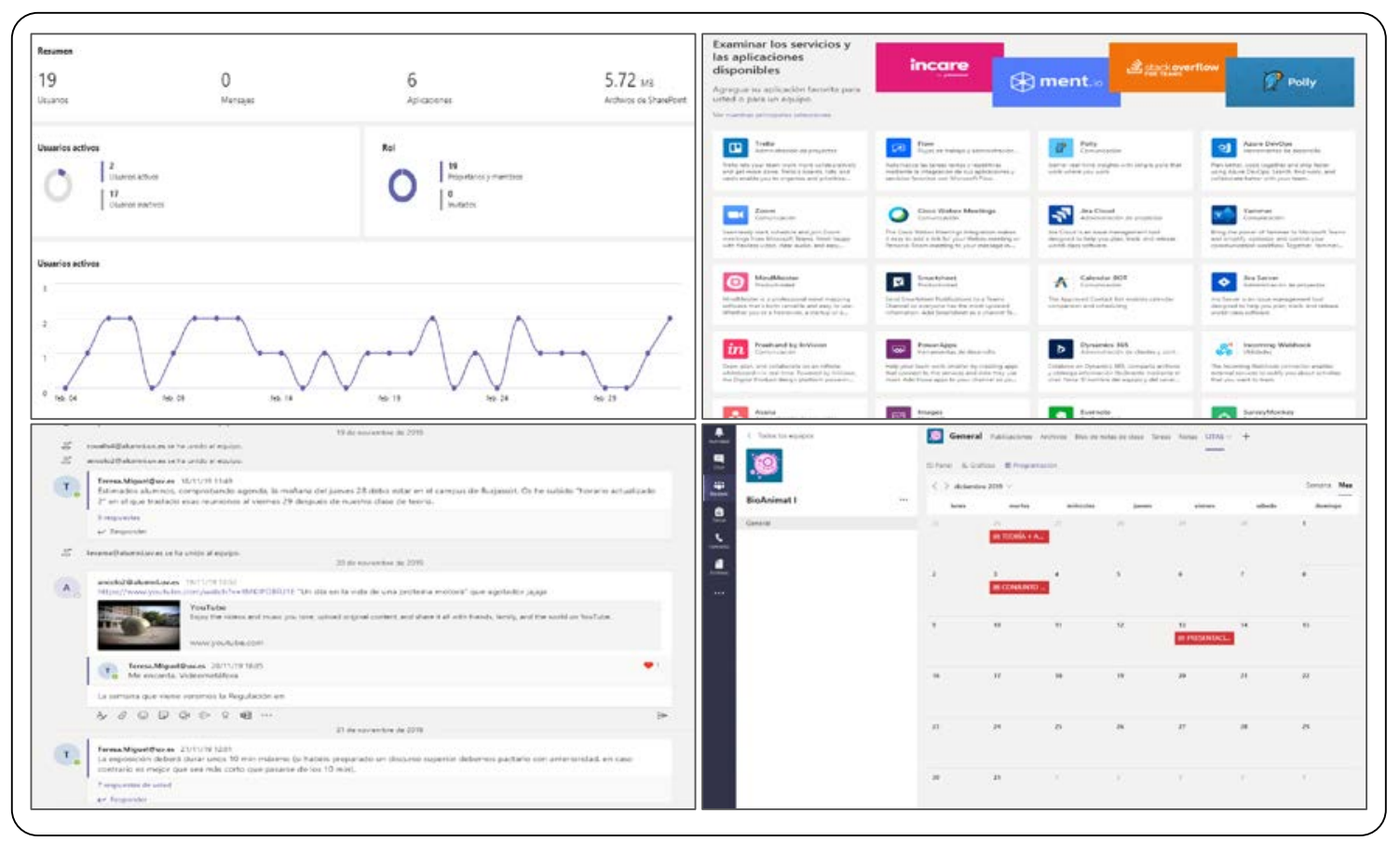

Fig 1. Ejemplos de las utilidades encontradas en Teams. De izquierda a derecha/de arriba abajo: monitorización del uso; aplicaciones incrustables; chat grupal; calendario de actividades con enlace al detalle de las tareas.

\subsection{Los objetos de aprendizaje se generan en plazo.}

Todos los grupos llegan a la presentación con una o dos animaciones completas para su presentación. Las animaciones creadas se recogen en la tabla 1.

Tabla 1. Relación de animaciones creadas por los diferentes grupos de trabajo

\section{Objetos de aprendizaje creados}

1 Glucosilación de proteínas en el RE

2 Biogénesis del núcleo

3 Transporte de proteínas lisosomiales

4 Endocitosis mediada por receptor

5 Ciclo del cromosoma

6 Recuperación de proteínas residentes del RE 
7 Secreción constitutiva frente a regulada

8 Dinámica de los microtúbulos

\subsection{El entusiasmo poco canalizado influye negativamente en la calidad.}

De los ocho grupos de trabajo, ninguno sigue el orden de trabajo que se explica y argumenta en clase y que se detalla en Teams. Ni uno solo de los grupos acude a la primera reunión con los contenidos a explicar trabajados y sin detectar los aspectos que mayores dificultades les plantean. Esto tiene consecuencias a lo largo de todo el desarrollo de la innovación y lleva a que los OA generados incluyan en todos los casos, algún error conceptual o visual, reduciendo su utilidad directa.

Las ganas de trabajar la competencia digital causan una primera reunión llena de bocetos en papel de las imágenes del proceso a grandes rasgos, en 4 casos. En los otros 4 casos, lleva directamente a bocetos digitales de la animación, con los movimientos de intercambio grosso modo a nivel subcelular pero sin el detalle de los contenidos abordables. En la segunda reunión presentan animaciones completas en vez de bocetos. En la tercera reunión se transmite por primera vez lo que se quiere contar. Se detectan carencias por lo que se abordan los aspectos que deben extenderse para la presentación. Solo 2 de los 8 grupos solicita participar en la cuarta reunión. Estos resultados inciden en la interrelación entre los objetivos 3 y 4. Logramos un buen desarrollo de la competencia digital y los alumnos manifiestan estar muy motivados en desarrollar esa competencia y en la creción de sus diseños, pero descuidan los contenidos.

\subsection{Los errores gráficos se compensan.}

Los grupos realizan la presentación de sus animaciones. Siete de las ocho incluyen algún error. El hecho de generar primero las animaciones antes de tener claro el discurso se entiende como origen de ello. Durante la exposición oral, los grupos ilustran su explicación con su OA. Al finalizar, cuestionan al público si son capaces de detectar los errores gráficos incluidos o las inconcreciones en la imagen. Algunos de los errores se muestran en la figura 2. Así se aborda el uso de los OA como pseudo-ApS dentro del objetivo 5 , que se desarrollará plenamente en próximas ediciones.

\section{Conclusiones}

Tras el desarrollo de esta primera fase del proyecto, podemos extraer algunas conclusiones en relación a los primeros objetivos planteados. En primer lugar, la motivación de los alumnos ha sido muy alta. La aceptación de la actividad, a pesar de suponer una carga de trabajo muy superior a la opción alternativa, fue del $100 \%$ del grupo. Sin embargo, y dado el progreso de la implementación, podemos concluir que, si bien la motivación es un elemento necesario y fundamental, no es suficiente para que la ejecución se satisfactoria.

A pesar del entusiasmo en las sesiones, la utilización de Teams fue baja. La mitad de los miembros de la clase accedieron, y de ellos solo la mitad participaron activamente de manera virtual. De aquí, podemos concluir que la no obligatoriedad de las acciones, conduce a una pérdida del seguimiento. La "recomendación" del profesor parece entenderse más como un capricho del docente, de modo que, si no 
existe una traslación directa sobre la calificación, no se entiende su función favorecedora para la consecución de los objetivos propuestos.

Los alumnos agradecen desarrollar su competencia digital y tener protagonismo en la creación de objetos de aprendizaje. Sin embargo, siendo el primer curso de grado, parece que canalizan de manera poco eficaz ese entusiasmo. Les cuesta seguir las pautas y recomendaciones pues comienzan el trabajo por lo que, citando sus palabras "les hace más ilusión". Así, podemos concluir que son muy conscientes del impacto visual de los materiales. Sin embargo, no tienen esa conciencia sobre la importancia de un buen diseño previo.

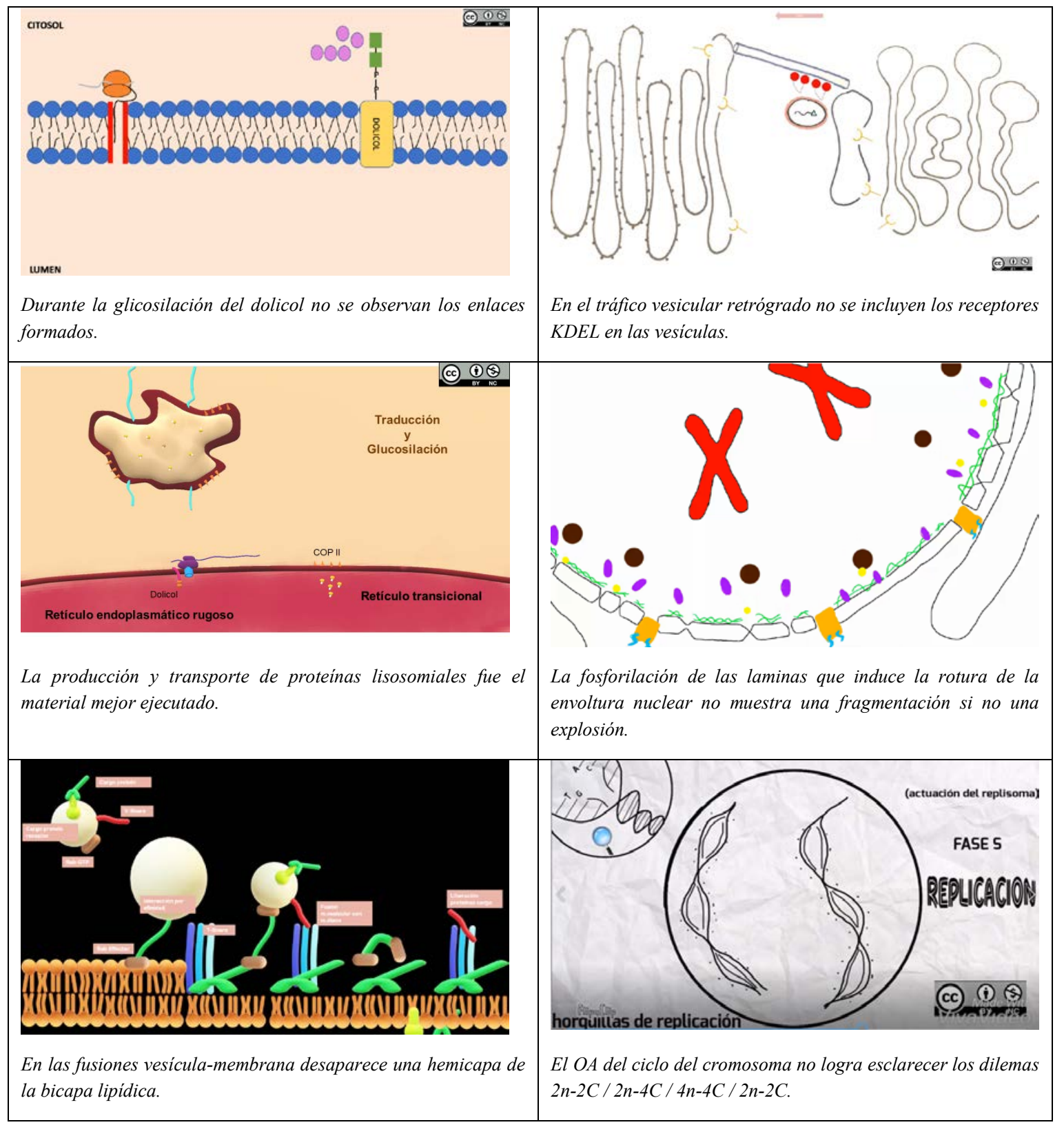

Fig 2. Representación de fragmentos de algunos de los objetos de aprendizaje creados por los alumnos. La figura muestra algunos de los defectos detectados, sobre los que se pudo trabajar en el aula el día de la exposición. 
Por último, se debe mencionar la buena disposición para adaptarse a los cambios. Dado el enfoque erróneo por parte de muchos, para seguir las instrucciones con el orden lógico pedagógico, sí que mostraron buena flexibilidad para adaptar la exposición, como un momento en el que mostrar, por un lado lo que se hizo bien, pero también lo que se hizo mal. De esta manera, los objetos de aprendizaje creados, a pesar de incluir diferentes errores, sirvieron como herramienta para incrementar la atención del público de cara a detectar esos errores y a elaborar comentarios constructivos sobre el conocimiento derivado.

En definitiva, la actividad ha sido muy satisfactoria. Algunos de los materiales son realmente buenos desde un punto de vista técnico y el alumnado con menor competencia digital -aparentemente- encontró herramientas con las que mejorarlo. Así, el plan continua y el próximo año los alumnos de $1^{\circ}$ del grado en Medicina podrán continuar mejorando y complementando objetos de aprendizaje sobre estos y otros aspectos de la Biología Celular.

\section{Referencias}

LUJÁN-GARCÍA, C.I. (1999). La motivación: Un factor relevante en el proceso de enseñanza/aprendizaje de lenguas extranjeras. Boletín Millares Carlo, (18), 269-278.

MARQUÈS, P. (2000). Ventajas e inconvenientes del material multimedia educativo. Departamento de Pedagogía Aplicada, Facultad de Educación, UAB <http://peremarques.net/ventajas.htm> [Consulta: 22 de marzo de 2020].

NMC and the EDUCAUSE Learning Initiative (ELI). Educase Library $<$ https://library.educause.edu/search\#?page=1\&publicationandcollection_search=EDUCAUSE\%20Learning\%20Initi ative\%20(ELI)\%7CNew\%20Media\%20Consortium\%20(NMC)\&sortBy=relevance\&sortOrder=asc $>$ [Consulta: 22 de marzo de 2020]

POLANCO, A. (2005). "La motivación en los estudiantes universitarios". Revista Electrónica "Actualidades Investigativas en Educación. Vol. 5, núm. 2, pp. 1-13<http://www.redalyc.org/articulo.oa?id=44750219> [Consulta: 18 de marzo de 2018]

RONCEL-VEGA, V. M. (2007). El rendimiento en ELE en la enseñanza reglada: un modelo explicativo. MarcoELE: Revista De Didáctica, (5).

SALINAS, J. (1996): "Multimedia en los procesos de enseñanza - aprendizaje: Elementos de discusión". Ponencia en el Encuentro de Computación Educativa. Santiago de Chile, 2-4 mayo.

TEJEDOR, F.J. Y GARCÍA-VALCÁRCEL, A. (2007). "Causas del bajo rendimiento del estudiante universitario (en opinión de los profesores y alumnos). Propuestas de mejora en el marco del EEES”. Revista de Educación, vol. 342, p. $443-473$ 